\title{
Effect of the structure on biological and photocatalytic activity of transparent titania thin-film coatings
}

\author{
Damian Wojcieszak ${ }^{1, *}$, Michą Mazur ${ }^{1}$, Danuta KaCZMareK ${ }^{1}$, Agata Poniedziałek ${ }^{1}$, \\ Piotr Domanowski ${ }^{2}$, BogumiŁa SzPonar ${ }^{3}$, Aleksandra CZajKowska ${ }^{3}$, \\ ANDRZEJ GAMIAN ${ }^{3}$ \\ ${ }^{1}$ Faculty of Microsystem Electronics and Photonics, Wroclaw University of Technology, Janiszewskiego 11/17, \\ 50-372 Wroclaw, Poland \\ ${ }^{2}$ Faculty of Mechanical Engineering, University of Technology and Life Sciences in Bydgoszcz, Kaliskiego 7, \\ 85-796 Bydgoszcz, Poland \\ ${ }^{3}$ Institute of Immunology and Experimental Therapy, Polish Academy of Sciences, Rudolfa Weigla 12, \\ 53-114 Wroclaw, Poland
}

\begin{abstract}
In this work, the effect of titanium dioxide $\left(\mathrm{TiO}_{2}\right)$ thin film microstructure on photocatalytic and biological activity was described. The films were prepared by low-pressure and high-energy magnetron sputtering processes. The structural investigations performed by X-ray diffraction revealed that the films from both the processes were nanocrystalline. It was found that $\mathrm{TiO}_{2}$ prepared by low-pressure process had the anatase structure with crystallites in size of $20 \mathrm{~nm}$, while the film deposited in high-energy process had the rutile form with crystallites in size of $5 \mathrm{~nm}$. The analysis of surface topography with the aid of optical profiler showed that all prepared films were homogenous and their roughness was lower than $1 \mathrm{~nm}$. The wettability studies revealed hydrophilic nature of both films. The values of water contact angle obtained for anatase and rutile films were equal to $40^{\circ}$ and $49^{\circ}$, respectively. Both types of the thin films were photocatalitycally active, but rutile exhibited higher decomposition rate as compared to anatase. During the photocatalytic reaction in the presence of $\mathrm{TiO}_{2}$-rutile film after 12 hours of UV-Vis irradiation $30 \%$ of phenol was decomposed, whereas in case of $\mathrm{TiO}_{2}$-anatase it was only $10 \%$. Moreover, the influence of as-deposited coatings on the growth of selected microbes (Staphylococcus aureus, Escherichia coli, Candida albicans) was examined. It was found that the structural properties of $\mathrm{TiO}_{2}$ had an effect on biological activity of these films.
\end{abstract}

Keywords: $\mathrm{TiO}_{2}$; thin film; nanocrystalline structure;antibacterial properties; photocatalytic activity

(C) Wroclaw University of Technology.

\section{Introduction}

Rapid progress in engineering of biofunctional thin-film coatings has recently been observed. It is directly related to the increase of nosocomial infections and larger impact of microorganisms on a human life. For this reason, there is a necessity to find a new method for neutralization of microorganisms. Application of coatings, e.g. based on metal oxides, which exhibit antimicrobial and antifungal activity is very attractive solution to this problem. One of the materials that could be used for this purpose is titanium dioxide due to its well known bioactivity related to catalytic

*E-mail: damian.wojcieszak@pwr.edu.pl properties [1-3]. $\mathrm{TiO}_{2}$ exhibits high chemical stability, it is also a non-toxic material, cheap in production [1-4]. Properties of titania can be modified in different ways, e.g. by selection of deposition parameters, doping with different elements (e.g. copper, silver), or by post-process treatment (annealing in high temperature) $[1,5,6]$.

Nowadays, the major way to increase the activity of titania is manufacturing it in a nanocrystalline form. The change of crystallites size can modify wettability of the surface, which results in hydrophobic or hydrophilic properties. Moreover, decrease of crystallites size leads to an increase of the hardness and scratch resistance of such coatings, so they can be used in manufacturing of protective films for window glass-panels, displays or 
eyeglasses [7]. The photocatalytic properties of titanium dioxide provide a biocidal effect due to oxidation of cell membrane. In consequence, vital functions and cellular processes of microorganisms are being impaired and this leads to the cell death $[2,8]$. Another method of microorganism destruction is its penetration by $\mathrm{TiO}_{2}$ nanoparticles without a complete destruction of a cell membrane. Therefore, the decomposition process can occur inside the cell and result in biocidal effect $[1,9,10]$.

The properties of titanium dioxide are related to its structure. $\mathrm{TiO}_{2}$ films usually occur in anatase or rutile form. However, mixtures of these phases (anatase - rutile), or fully amorphous titania can be also obtained [10-15]. Coatings with anatase structure are being used for photocatalytic sterilization much more often than the rutile ones due to their higher surface area and higher degree of surface hydroxylation, providing a positive effect on decomposition ratio $[2,9]$. Films with the rutile phase have less amount of active sites and hydroxyl groups on the surface and shorter time of recombination between electron-hole pairs as compared to $\mathrm{TiO}_{2}$-anatase $[16,17]$. Usually, $\mathrm{TiO}_{2}$ with rutile structure can be obtained by annealing of anatase at temperature above $700{ }^{\circ} \mathrm{C}$. However, annealing process leads to the growth of crystallites, which often has a negative impact on the properties of the material [11]. In the literature there are many, often contradictory, reports on the activity of the various structure phases of $\mathrm{TiO}_{2}$. Usually, in the case of antibacterial properties the best efficiency exhibit films with mixed phase, where the content of anatase ranges between 70 and $75 \%$, while for rutile it is ca. 25 to $30 \%[4,9]$. The dispersion of these values is most probably a consequence of small differences in crystallite sizes, active surface area, number of defects, level of oxygen adsorption and number of hydroxyl groups on the surface [9]. It was found that some of these parameters have a significant impact on antibacterial activity. In particular, the surface area and crystallites size have a crucial impact on the biocidal effectiveness of titania [9]. Some studies [11] confirmed existence of the optimal crystallites size of about $10 \mathrm{~nm}$, when the photocatalytic oxidation of the organic substrates reached maximum efficiency. There are many examples of bactericidal effect of $\mathrm{TiO}_{2}[3,9]$. For example Markowska Szczupak et at. [9] showed that this material is well suited for photocatalytic destruction of microorganisms. They found that the activity of titanium dioxide is the highest in contact with viruses, bacteria (both, gram negative and positive), endospores and yeasts, while it does not have such impact on fungi.

In this paper the effect of $\mathrm{TiO}_{2}$ microstructure and surface properties on photocatalytic and bactericidal activity is discussed. $\mathrm{TiO}_{2}$ films were prepared by innovative low-pressure and high energy magnetron sputtering processes and directly after deposition the coatings with anatase or rutile structure were obtained.

\section{Experimental details}

$\mathrm{TiO}_{2}$ thin films were manufactured by a lowpressure and high-energy sputtering processes. In both cases, a Ti metallic disc was sputtered in pure oxygen plasma $(<0.1 \mathrm{~Pa})$. High-energy process is a modification of low-pressure process, which was described in details elsewhere [18]. The main idea was to increase the energy of sputtered titanium particles by applying higher voltage of the magnetron supply and to decrease the cooling level of Ti-target [19]. Due to such changes it was possible to obtain $\mathrm{TiO}_{2}$ coatings with anatase or rutile structures directly after deposition in low-pressure and high energy processes, respectively. In the case of both processes, thin films were deposited on several $\mathrm{SiO}_{2}$ substrates (each in size of $2 \times 2 \mathrm{~cm}^{2}$ ). Part of the samples was cut into smaller pieces $\left(1 \times 1 \mathrm{~cm}^{2}\right)$ and used for biological studies.

Structural properties of prepared films were determined based on the results of the X-ray diffraction (XRD) method. For the experiments, DRON-2 powder diffractometer with Co K $\alpha$ X-ray $(\lambda=1.78897 \AA)$ was used. The average size of crystallites was calculated according to the Scherrer's formula. In the case of $\mathrm{TiO}_{2}$ anatase the full width at half maximum of the peak corresponding to the (1 110$)$ crystal plane was used, while for the rutile it was (1 $\left.\begin{array}{lll}1 & 0 & 1\end{array}\right)$ plane. 
The optical properties of both films were determined by optical transmission measurements. For the experiments, OceanOptics QE 65000 UV-Vis spectrophotometer coupled with Mikropack DH2000-BAL deuterium-halogen light source were used. Thanks to these measurements the analysis of thickness, refractive index and extinction coefficient were performed for both thin films with the aid of FTG FilmStar software. The thickness of anatase and rutile thin films was equal to $180 \mathrm{~nm}$ and $281 \mathrm{~nm}$, respectively.

Photocatalytic properties of the manufactured films were determined from the results of phenol decomposition reaction. Phenol is an aromatic organic compound produced on a large scale [20]. It is necessary for preparation of polycarbonates, epoxies, detergents, herbicides and numerous pharmaceutical drugs [20]. So its presence in our environment is high. Unfortunately, phenol causes a lot of harmful effects [21]. For this reason its decomposition has important meaning. In the case of our experiment, aqueous solution $(200 \mathrm{~mL})$ of phenol (concentration - $10 \mathrm{mg} / \mathrm{L}$ ) was used. The experiment was carried out under UV-Vis light source in water cooled quartz-glass reactor, under agitation with a magnetic stirrer $(800 \mathrm{rpm})$ in order to provide homogenous concentration of the solution in entire volume. The sample size was $6 \mathrm{~cm}^{2}$. To determine the change of phenol concentration, the samples containing its solution were withdrawn from the reactor every 2 hours for 12 hours and analyzed by OceanOptics QE 65000 UV-Vis spectrophotometer coupled with Mikropack DH-2000BAL deuterium-halogen light source. The concentration was calculated from the phenol absorption peak at ca. $270 \mathrm{~nm}$ by a calibration curve.

Surface topography of the coatings was determined with the aid of CCI Theta Lite optical profiler (Taylor Hobson). The value of arithmetic mean deviation of the roughness profile $(\mathrm{Sa})$ was determined by the method based on the threedimensional profile. For surface wettability measurements the Theta Lite (Attension) tensiometer stand was used. Distilled water, ethylene glycol and ethanol were used for the contact angle measurements. The wettability of different solid materials was also characterized by the method proposed by Zisman [22]. Using a series of liquids with different surface tensions, a graph of $\cos \theta$ vs. $\gamma$ was determined. Critical surface tension equals the surface tension at which the plotted line intersects 1.0 and it is often interpreted as the highest value of surface tension of a liquid, which will completely wet the solid surface [22, 23].

Bactericidal and fungicidal effect of $\mathrm{TiO}_{2}$ coatings was studied on bacterial strains: Escherichia coli PCM 144, Staphylococcus aureus PCM 2602 and fungi (yeast) Candida albicans PCM 2566. Thin films deposited on glass substrates $\left(1 \mathrm{~cm}^{2}\right)$ were exposed to $1.5 \mathrm{~mL}$ of bacteria or fungi suspension in PBS (Phosphate-Buffer Saline) of known dilution on 24-hole test plate (Corning Costar cell culture plates, 3524). The initial optical density of prepared solutions (OD) was 0.5 in McFarland scale, but before the use they were diluted by $10^{4}$ times. After 2, 4, 6 and 24 hours, the suspension was collected and incubated (in dark conditions, at $37^{\circ} \mathrm{C}$ ) on agar medium over 24 -hours. The number of colony forming units per millilitre (cfu/mL) was determined with the aid of dilution method. The final quantitative result was an average value of three individual tests. Antimicrobial tests for both films were controlled by the growth of the cultures from the solutions collected from suspensions without thin films.

\section{Results and discussion}

The microstructure of $\mathrm{TiO}_{2}$ thin films was determined by X-ray diffraction measurements. The XRD patterns of manufactured films are presented in Fig. 1. The results have shown that both the coatings were nanocrystalline. For titania films from low-pressure process the anatase structure with crystallites in size of $19.9 \mathrm{~nm}$ was obtained. In the case of high-energy process, the rutile phase with crystallites in size of $4.6 \mathrm{~nm}$ was obtained (Table 1). It is worth to emphasizing that these results are quite innovative due to the formation of rutile structure without additional post-process annealing. Moreover, these films had 4-times lower crystallites size as-compared to the coating from low-pressure process. The comparison of 
Table 1. Structural properties of $\mathrm{TiO}_{2}$ thin films determined based on the results of XRD.

\begin{tabular}{ccccccccc}
\hline Thin film & Process & Phase & Crystal plane & $\mathrm{D}[\mathrm{nm}]$ & $\mathrm{d}[\mathrm{nm}]$ & $\mathrm{d}$ PDF [nm] & $\Delta \mathrm{d}(\%)$ & PDF card \\
\hline \hline $\mathrm{TiO}_{2}$ & low-pressure & anatase & $\left(\begin{array}{lll}1 & 0 & 1\end{array}\right)$ & 19.9 & 0.3519 & $0.3520[24]$ & -0.03 & $21-1272[24]$ \\
$\mathrm{TiO}_{2}$ & high-energy & rutile & $\left(\begin{array}{lll}1 & 1 & 0\end{array}\right)$ & 4.6 & 0.3240 & $0.3247[25]$ & -0.21 & $21-1276[25]$ \\
\hline
\end{tabular}

$\mathrm{D}$ - average crystallites size, $\mathrm{d}$ - interplanar distance, $\mathrm{d}_{\mathrm{PDF}}$ - standard interplanar distance, $\Delta \mathrm{d}$ - relative distance between $\mathrm{d}$ and $\mathrm{d}_{\mathrm{PDF}}, \Delta \mathrm{d}=\left[\left(\mathrm{d}-\mathrm{d}_{\mathrm{PDF}}\right) / \mathrm{d}_{\mathrm{PDF}}\right] \cdot 100 \%$

interplanar distances (d) of both films with standard ones $\left(\mathrm{d}_{\mathrm{PDF}}\right)$ showed that they were similar. The value of the difference in relative distances between $\mathrm{d}$ (measured interplanar distance) and $\mathrm{d}_{\mathrm{PDF}}$ (standard interplanar distance from PDF card) of $\mathrm{TiO}_{2}$-anatase was equal to $-0.03 \%$, while for the $\mathrm{TiO}_{2}$-rutile it was $-0.21 \%$. Therefore, it can be stated that no significant stress occurred in the lattice of both the films.

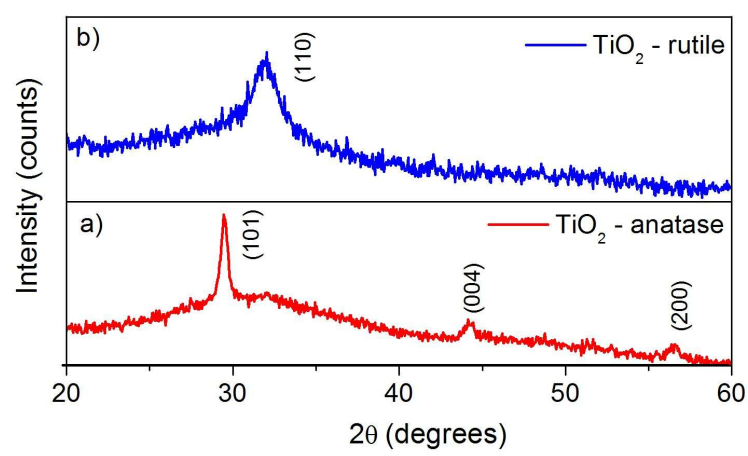

Fig. 1. XRD patterns of a) $\mathrm{TiO}_{2}$ - anatase thin film from low-pressure process and b) $\mathrm{TiO}_{2}-$ rutile thin film from high-energy process.

The effect of deposition process parameters on the optical properties of $\mathrm{TiO}_{2}$ films was also examined. The transmission characteristics of the coatings are presented in Fig. 2. The thickness of anatase and rutile thin films was equal to $180 \mathrm{~nm}$ and $281 \mathrm{~nm}$, respectively. Both titania thin films had high transparency in the visible light wavelength range. The average transmittance of prepared thin films was equal to ca. $85 \%$ and $80 \%$ for anatase and rutile coatings, respectively. The type of crystal structure affected the position of fundamental absorption edge ( $\left.\lambda_{\text {cut-off }}\right)$. The value of $\lambda_{\text {cut-off }}$ for anatase films was equal to $330 \mathrm{~nm}$, while for rutile it was $344 \mathrm{~nm}$. Therefore, a red shift was observed for the films with the rutile phase. In the case of refractive index $n$ it was considerably higher for rutile films. At the $550 \mathrm{~nm}$ wavelength it was equal to 2.29 and 2.01 for $\mathrm{TiO}_{2}$ thin films with rutile and anatase structure, respectively. Extinction coefficient $\mathrm{k}$ value for both the thin films was small and rather similar to each other. In turn, this may testify low absorption of the light in the visible wavelength.

Modification of sputtering process parameters had an effect on photocatalytic activity of $\mathrm{TiO}_{2}$. The results of phenol decomposition showed that after 12 hours of UV-Vis light exposure of the sample with anatase structure $10 \%$ of the dye was decomposed. In the case of the film with rutile structure it was $30 \%$ (Fig. 3). An increase of the activity of $\mathrm{TiO}_{2}$ films with the rutile structure might be related to their crystallites size, which were 4-times smaller as compared to the titania film with anatase structure. Smaller crystallites of the coating from high-energy sputtering process had a direct effect on the increase of the level of surface roughness and surface active area.

The surface topography was also examined by roughness measurements with the aid of optical profiler (Fig. 4). The results testify that both the nanocrystalline $\mathrm{TiO}_{2}$ films were homogenous. The roughness of rutile structure was $0.6 \mathrm{~nm}$, while for anatase it was $0.8 \mathrm{~nm}$. Taking into consideration the results of XRD studies, it can be assumed that titania formed in high-energy process had a surface, which was covered by considerably smaller grains with lower height and therefore it was flatter. However, the results from optical profiler have shown that the roughness level of both films was similar (Fig. 4).

Topography of such nanocrystalline films had an effect on the wettability. It was found that in 

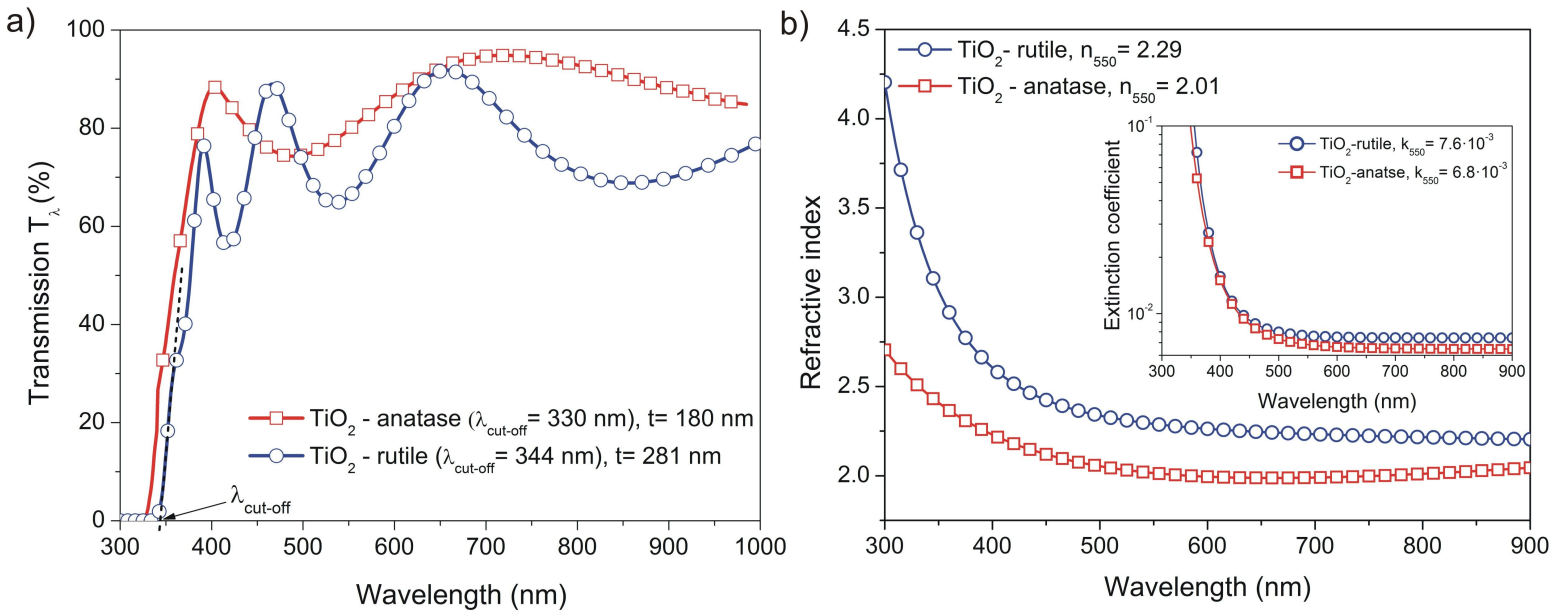

Fig. 2. Transmission characteristics (a) and refractive index (b) of $\mathrm{TiO}_{2}$ thin films with anatase and rutile structure.

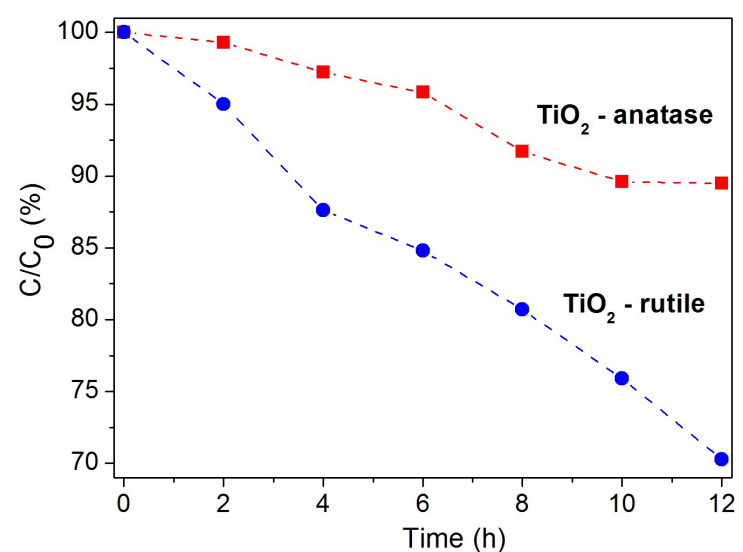

Fig. 3. Photocatalytic activity of $\mathrm{TiO}_{2}$ thin films with anatase and rutile structure based on phenol decomposition under UV-Vis light exposure.

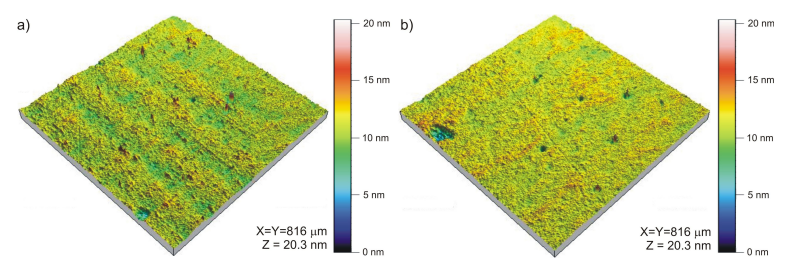

Fig. 4. Surface topography of $\mathrm{TiO}_{2}$ thin films with a) anatase and $b$ ) rutile structure.

the case of the film with anatase structure, the water contact angle was equal to $40.3^{\circ}$, while for the rutile one it was about $49^{\circ}$. Therefore, both titania coatings were hydrophilic, but lower roughness caused an increase of the water wetting angle. Wettability experiments were also carried out with the use of ethylene glycol and ethanol. These measurements allowed calculation of the critical surface tension. It was found that for $\mathrm{TiO}_{2}$-anatase the value of this parameter was equal to $23.15 \mathrm{mN} / \mathrm{m}$, while for $\mathrm{TiO}_{2}-$ rutile it was $21.33 \mathrm{mN} / \mathrm{m}$ (Fig. 5). It indicates that both the thin films had similar wettability.
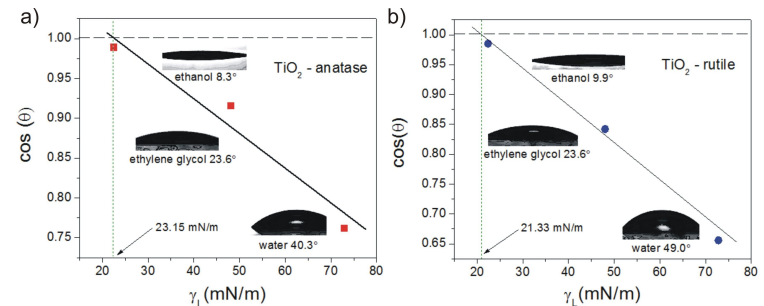

Fig. 5. Results of water contact angle and critical surface tension measurements for $\mathrm{TiO}_{2}$ thin films with a) anatase and b) rutile structure.

Biological activity was analyzed taking into consideration the structural and surface properties of prepared nanocrystalline films. Due to the relation of photocatalytic activity with destruction of microorganisms, the experiments with bacteria and fungi were carried out in dark conditions. The results showed that only rutile thin film exhibited some antibacterial properties against Staphylococcus aureus, but this effect was weak. Due to low magnitude of the colony number decrease it 
a)

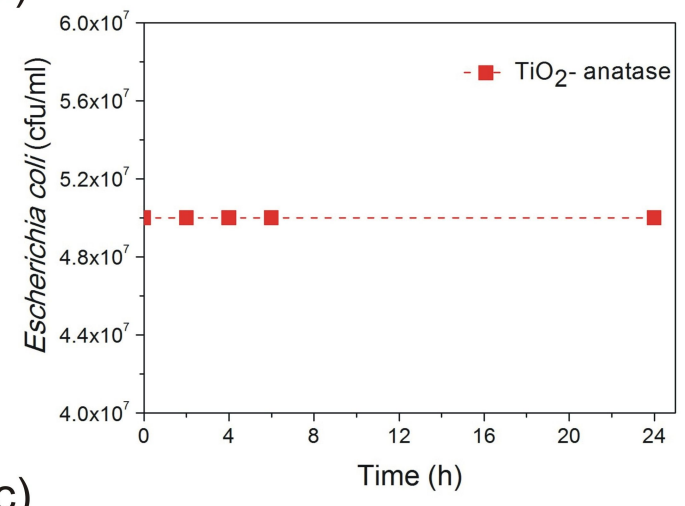

c)

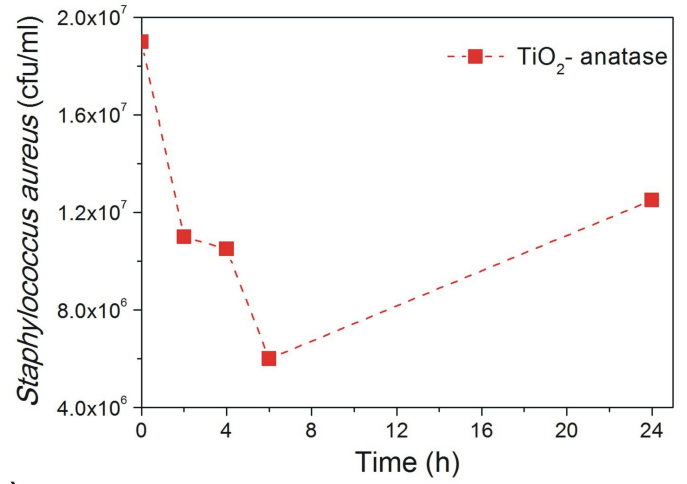

e)

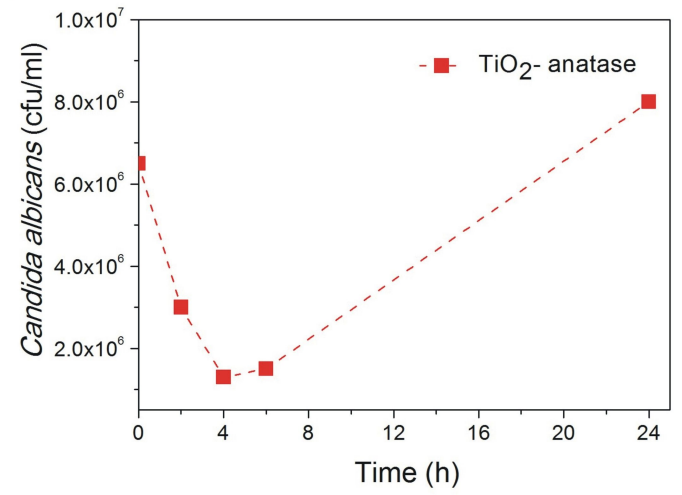

b)

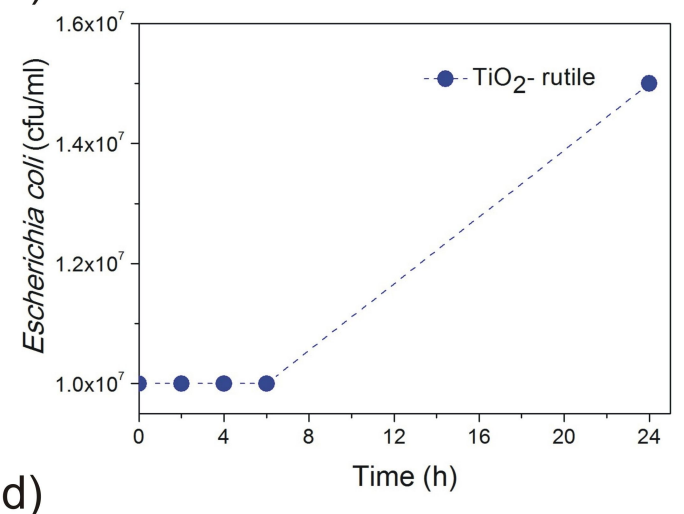

d)

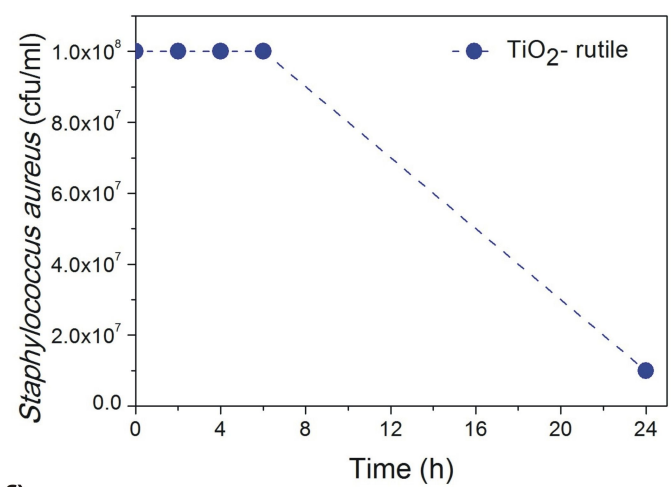

f)

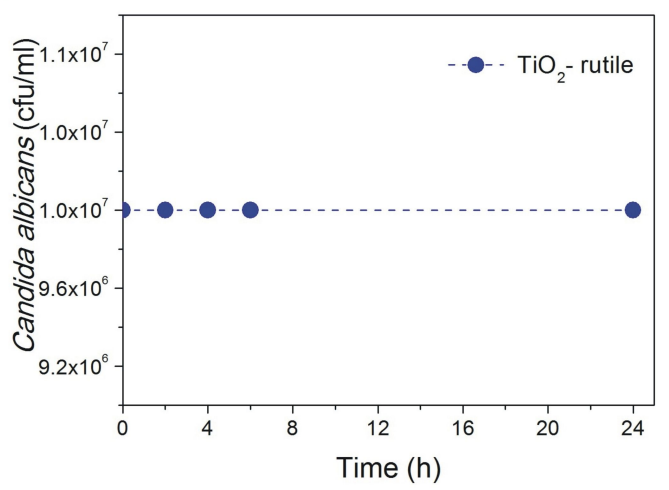

Fig. 6. Biological activity in dark conditions of $\mathrm{TiO}_{2}$ thin film with anatase (a, c, e) and rutile (b, d, f) structure against Eschericha coli (a,b), Staphylococcus aureus (c, d) and Candida albicans (e, f).

could be considered as a bacteriostatic. None of the tested films exhibited fungicidal or bactericidal activity against Candida albicans or Escherichia coli (Fig. 6). In the case of titanium dioxide with anatase structure, in experiments with Staphylococcus aureus and Candida albicans a weak antimicrobial activity in first four hours of incubation was observed, but extended exposure resulted in intense growth of these microorganisms.

\section{Summary}

The effect of the structure of titanium dioxide films on their photocatalytic and biological activity was described. The rutile and anatase films were prepared by magnetron sputtering method. The thin film deposited in low-pressure process had anatase structure with crystallites in size of about $20 \mathrm{~nm}$, while the coatings deposited by high-energy 
process had rutile structure with crystallites in size of about $5 \mathrm{~nm}$. Both coatings were well transparent in the visible light wavelength range $(80-85 \%)$. It was found that the modification of deposition process parameters, except an impact on the type of structure and crystallites size, had also an influence on photocatalytic activity, surface roughness and wettability. The studies revealed that nanocrystalline titania with anatase structure decomposed $10 \%$ of phenol, while the rutile one decomposed $30 \%$ of phenol after 12 hours of exposition to UV-Vis light. Moreover, only $\mathrm{TiO}_{2}$ built from rutile crystallites exhibited antimicrobial activity in contact with Staphylococcus aureus (in dark conditions), but this effect was weak and it corresponded rather to bacteriostaticity. The activity of this film was related to finer crystalline structure, which in turn resulted in an increase of the surface active area and decreased hydrophilic properties of the surface.

\section{Acknowledgements}

This work was co-financed by the NCN as research project number DEC-2012/07/B/ST8/03760. Authors would also like to acknowledge the financial support from Ministry of Science and Higher Education within the "IUVENTUS Plus" program in the years 2015-2017, project no. IP2014 051673 and from statutory sources B50045.

\section{References}

[1] Pal B., Singh I., Angrish K., Aminedi R., Das N., Mater. Chem. Phys., (2012), 21.

[2] Yu B., LeUnG K.M., GuO Q., LAU W.M., YANG J., Nanotechnology, 22 (2011), 1.

[3] Hou X., Ma H., Liu F., Deng J., Ai Y., Zhao X., MAO D., Li D., LiAo B., J. Hazard. Mater., 299 (2015), 59.

[4] Yeung K.L., Leung W.K., Yao N., CaO S., Catal. Today 143 (2009), 218.

[5] Mathews S., Hans M., Mucklich F., SoLIOZA M., Appl. Environ. Microbiol., (2013), 1.

[6] Santo C. E., Lam E. W., Elowsky C. E., Quaranta D., Domaille D. W., Chang J., Grass G., App. En. Microbiol., 77 (2011), 794.
[7] Xi B., Verma L. K., Bhatia C. S., Danner A. J., YANG H., Zeng H. C., ACS Appl. Mater. Interfaces, (2012), 1093.

[8] Maness P., Smolinski S., Blake D.M. Huang Z., Wolfrum E.J., Jacoby W.A., App. En. Microbiol., 65 (1999), 4094.

[9] MarkowsKa-SzczupaK A., Ulfig K., Morawski A.W., Catal. Today 169 (2011), 249.

[10] Fujishima A., Zhang X., Tryk D., Surf. Sci. Rep., 63 (2008), 515.

[11] Carp O., Huisman C.L., Reller A., Prog. Solid State Ch., 32 (2004), 33.

[12] YU J.C., Ho W., YU J., YIP H., WONG P.K., ZHAO J., Sci. Tech., 39 (2005), 1175.

[13] Ohtani B., Ogawa Y., Nishimoto S., J. Phys. Chem., 101 (1997), 3746.

[14] Fujishima A., Rao T.N., Tryk D.A., J. Photoch. Photobio. C 1 (2000), 1.

[15] Choi J., KIм K., ChоY K., Он K., KIм K., Wiley InterScience, (2006), 353.

[16] LiU L., Zhao H., Andino J.M., Li Y., ACS Catalysis 2 (2012), 1817.

[17] Linsebigler A.L., Lu G., Yates J.T., Chem. Rev. 95 (1995), 735.

[18] Kaczmarek D., DomaradzKi J., Wojcieszak D., Prociow E., Mazur M., Placido F., Lapp S., $J$ Nano Res. 18/19 (2012), 195.

[19] Daviosdottira S., Shabadib R., Galcac A.C., ANDERSEND I.H., Dirscherle K., Ambata R., Appl. Surf. Sci. 313 (2014), 677.

[20] Weber M., Weber M., Kleine-Boymann M., Ullmann's Encyclopedia of Industrial Chemistry (2004).

[21] LIN T.M., LEE S.S., LAI C.S., LIN S.D., Burns: J. of Int. Soc. for Burn Inj. 32 (2006), 517.

[22] Sharfin E., Zisman W.A., J. Phys. Chem. 64 (1960), 519

[23] Kwok D.Y., Neumann A.W., Adv. Coll. Interfac. 81 (1999), 167

[24] Powder Diffraction File, Joint Committee on Powder Diffraction Standards ASTM, (1967). Philadelphia, PA, Card 21-1272.

[25] Powder Diffraction File, Joint Committee on Powder Diffraction Standards ASTM, (1967). Philadelphia, PA, Card 21-1276.
Received 2016-04-20 Accepted 2016-08-29 